\title{
MEMBANGUN CUSTOMER RELATIONSHIP MANAGEMENT (CRM) PADA USAHA RITEL PASAR TRADISIONAL DI KOTA TANGERANG SELATAN
}

\author{
Thio Lie Sha ${ }^{1}$, M. Tony Nawawi ${ }^{2}$, dan Rosmita Rasyid ${ }^{3}$ \\ ${ }^{1}$ Fakultas Ekonomi \& Bisnis Universitas Tarumanagara Jakarta Indonesia \\ Email: theol@fe.untar.ac.id \\ ${ }^{2}$ Fakultas Ekonomi \& Bisnis Universitas Tarumanagara Jakarta Indonesia \\ Email: tonyn@fe.untar.ac.id \\ ${ }^{3}$ Fakultas Ekonomi \& Bisnis Universitas Tarumanagara Jakarta Indonesia \\ Email: rosmitar@fe.untar.ac.id
}

\begin{abstract}
In community service activities that have been carried out in Tangerang City, the aim of this activity is to conduct training in retail businesses in South Tangerang, in building relationships with customers. Providing knowledge on how to build good relationships with customers is expected to increase customer loyalty. This activity refers to the results of internal grant research from PKM team members on customer relationship management (CRM). For retail businesses, it is very important to build customer relationship management (CRM) in increasing and maintaining loyal customers. The partner that is used as a place of activity is engaged in retail trading in eight traditional markets in South Tangerang, and has been in business for 6 years. With preliminary observations made on partners, several problems faced by these partners were identified, including a). Lack of knowledge of partners in doing good relationships with customers. $b$ ) lack of knowledge of partners to analyze customer relationship management (CRM) programs in maintaining customers. Based on the analysis of partner problems, there is still weak knowledge of customer relationship management (CRM) so that partners have not been able to build relationships with customers. The method offered in this activity is training online retail business owners. The results of this activity indicate that the partners are very enthusiastic in listening to and discussing the CRM material delivered by the PKM TEAM. Thus the understanding of partners about CRM will be further improved.
\end{abstract}

Keyword: customer relationship management (CRM), retail business, training

\begin{abstract}
ABSTRAK
Pada kegiatan pengabdian kepada masyarakat yang telah dilaksanakan di Kota Tangerang, yang bertujuan untuk kegiatan ini adalah melakukan pelatihan pada usaha ritel di Tangerang Selatan, dalam membangun hubungan dengan pelanggan. Dengan pembekalan pengetahuan tentang cara membangun hubungan yang baik dengan pelanggan diharapkan dapat meningkatkan loyalitas pelanggan. Kegiatan ini mengacu dari hasil penelitian hibah internal dari anggota tim PKM tentang customer relationship managemen (CRM). Bagi usaha ritel sangat penting membangun customer relationship managemen (CRM) dalam meningkatkan dan mempertahankan pelanggan yang setia. Mitra yang dijadikan tempat kegiatan adalah bergerak dalam bidang perdagangan eceran di pasar tradisional delapan Tangerang Selatan, dan sudah melakukan usaha selama 6 tahun. Dengan observasi awal yang dilakukan pada mitra teridentifikasi beberapa persoalan yang dihadapi mitra tersebut diantaranya a). Kurangnya pengetahuan mitra dalam melakukan hubungan yang baik dengan pelanggan. b) kurangnya pengetahuan mitra menganalisis program customer relationship managemen (CRM) dalam mempertahankan pelanggan. Berdasarkan analisis masalah mitra , masih lemahnya pengetahuan akan customer relationship managemen (CRM) sehingga mitra belum maтри membangun hubungan dengan pelanggan. Metode yang ditawarkan pada kegiatan ini adalah pelatihan kepada pemilik usaha ritel secara daring. Hasil kegiatan ini menunjukkan bahwa mitra sangat antusias dalam mendengarkan dan berdiskusi tentang materi CRM yang disampaikan oleh TIM PKM. Dengan demikian pemahaman mitra tentang CRM akan lebih meningkat.
\end{abstract}

Kata kunci: customer relationship managemen (CRM), usaha ritel, pelatihan

\section{PENDAHULUAN}

Secara luas, customer relationship management (CRM), merupakan suatu alat yang dapat diterima dan efektif bagi tindakan manajerial dalam mengumpulkan, menganalisis dan menterjemahkan informasi pelanggan yang amat berharga. CRM didasarkan pada prinsip bahwa mengembangkan hubungan dengan para pelanggan akan membuat pelanggan menjadi loyal. Konsep strategis dalam CRM adalah menghasilkan kepuasan pelanggan, kesetiaan, retensi pelanggan dan akhirnya akan 
meningkatkan profitability. CRM juga membantu salespeople bertemu konsumen dengan produk yang terbaik, sehingga akan meningkatkan penjualan perusahaan Hair (2014). Menurut Kotler \& Amstrong (2015) CRM adalah sebagai "keseluruhan proses membangun dan merawat hubungan baik dengan pelanggan yang menguntungkan dengan cara menyediakan/ memberikan nilai dan kepuasan pelanggan yang superior. Model kepuasan pelanggan bergantung pada analisis kebutuhan, harapan dan interaksi pelanggan dengan organisasi dan pelayanannya. Model kepuasan pelanggan terutama berkaitan dengan CRM untuk mendapatkan feedback mengenai persepsi pelanggan tentang organisasi dan performance-nya, serta tentang pemenuhan harapan pelanggan. Levy (2012).

Mitra yang dijadikan tempat kegiatan adalah bergerak dalam bidang perdagangan eceran di pasar tradisional delapan Tangerang Selatan sudah melakukan usaha selama 6 tahun. Melalui observasi awal yang dilakukan pada mitra teridentifikasi beberapa persoalan yang dihadapi mitra antara lain a). Kurangnya pengetahuan mitra dalam melakukan hubungan yang baik dengan pelanggan. b) kurangnya pengetahuan mitra menganalisis program CRM dalam mempertahankan pelanggan. Untuk itu kegiatan sebagai akademisi merasa penting untuk melakukan kegiatan PKM dalam upaya mengatasi persoalan mitra tersebut. PKM ini ,sebagai implementasi dari hasil penelitian tahun 2019 tentang CRM dari anggota Tim, Dimana penting nya CRM dalam menjalankan suatu bisnis. Melalui CRM akan mengubah pelanggan besi dan emas menjadi pelanggan platinum. Hasil penelitian menunjukkan bahwa menjalin hubungan baik dengan pelanggan merupakan hal yang seharusnya dilakukan oleh setiap perusahaan . baik perusahaan besar maupun kecil, swasta ataupun pemerintah. Setiap usaha dalam satu organisasi apapun harus selalu menjaga hubungan baik dengan pelanggan. Hal ini dikarenakan posisi dan keberadaan pelanggan sangat memberikan pengaruh dalam keberlangsungan usaha.

\section{METODE PELAKSANAAN PKM}

Berdasarkan hasil diskusi dengan pemilik toko ritel tentang pelakanaan kegiatan, dilakukan dengan memberikan pembekalan pengetahuan CRM. Untuk melaksanakan kegiatan sosialisasi ini, ada beberapa langkah yang perlu dilakukan.

a. Tim PKM sebagai tutor menghubungi pihak terkait, yaitu pemilik toko ritel ibu Wanti, untuk minta ijin melakukan sosialisasi.

b. Tim PKM sebagi tutor berkoordinasi dengan pemilik agar dapat memberikan jadwal untuk melakukan kegiatan sosialisasi.

c. Tim PKM sebagai tutor menyampaikan materi sosialisasi melalui ceramah, diskusi, dan tanya jawab. sosialisasi secara daring

d. Tutor mejelaskan tentang Customer relationship management yang harus dimiliki mitra semasa menjalankan usaha rirel

e. Pemilik dalam hal ini ibu Wanti dan karyawan toko mendengarkan dan memberikan respon pada tim PKM atas materi sosialisasi.

\section{HASIL DAN PEMBAHASAN KEGIATAN}

Usaha ritel didirikan di pasar modern delapan di alam Sutera Tangerang Selatan . Pasar 8 dibangun oleh PT Alam Sutera Realty Tbk adalah pusat perbelanjaan dalam bentuk pasar modern yang terletak di kawasan Alam Sutera, Tangerang. Pasar ini sendiri menjadi favorit warga setempat untuk mencari berbagai kebutuhan sehari-hari mereka dengan mudah dan harga yang terjangkau. Pasar 8 juga telah sukses menjadi wadah yang layak bagi para pengusaha lokal, baik kecil maupun menengah, untuk memperdagangkan produk-produk buatan mereka. Menjadi pasar yang saling 
menguntungkan bagi penjual dan pembeli, tidak mengherankan jika Pasar 8 bisa tetap unggul di tengah pusat perbelanjaan atau area komersial lainnya di kawasan Alam Sutera.

Berbagai produk yang dijual sangat beragam. Mulai dari produk bahan makanan atau kebutuhan dapur. sayuran, bumbu masak, daging, ayam, hingga seafood, produk-produk tersebut juga memiliki kualitas tidak kalah dari produk di supermarket dan dengan harga yang relative lebih murah. Sehingga warga senang menghabiskan waktu lama berbelanja di pasar ini. Pasar 8 juga menyediakan berbagai produk kebutuhan rumah tangga lain, seperti peralatan dapur, rumah, kamar mandi, hingga berbagai servis untuk rumah tangga, seperti laundry. Terdapat pula sejumlah tenant kuliner yang menjual beragam jenis makanan.

Selain itu Pasar 8 dirancang sebagai tempat berbelanja dan berjualan yang nyaman. Hal tersebut diterapkan lewat bangunannya yang membawa konsep modern. Meskipun berbentuk pasar, tempat ini bebas sumpek, bau, atau becek, karena lantainya sudah menggunakan marmer berkualitas. Di samping itu, toko masing-masing penjual ditata sedemikian rupa untuk memberi kesan lapang, sehingga lalu-lalang tetap lancar. Terdapat sekitar 150 unit ruko, 238 kios, dan 304 lapak di pasar ini. Semua unit dibangun dengan material berkualitas, serta hadir dalam berbagai tipe. Kebersihan di Pasar 8 tidak lupa menjadi fokus utama pengelola, sehingga berbelanja di sini memiliki kesan yang sama dengan di supermarket modern. Fasilitas pendukung di Pasar 8 pun tergolong lengkap. Di antaranya adalah area parkir yang luas, mampu menampung ratusan motor dan mobil, ATM center, toilet, dan keamanan selama 24 jam. Di sini juga tersedia kendaraan antar-jemput ke cluster-cluster di Alam Sutera.

Pasar 8 dibangun di lokasi yang strategis, sehingga mudah diakses oleh warga dari cluster mana pun. Tempat ini juga dikelilingi oleh berbagai area hiburan, seperti tempat rekreasi atau pusat perbelanjaan. Misalnya, Patriot Paintball Sport (350 m), Crystal Lane (450 m), Upside Down World (450 m), Little Jungle Playground (600 m), dan Living World Mall (900 m). Begitu pula dengan berbagai hotel, seperti Hotel Mercure Serpong Alam Sutera (750 m), Soll Marina Hotel (1,2 km), Starlet Hotel Serpong (1,7 km), dan Horison Grand Serpong (3,3 km).

Tempat ini pun dikelilingi oleh berbagai fasilitas pendidikan dan kesehatan. Beberapa sekolah yang berada dekat Pasar 8, antara lain SDN 01 Serpong (180 m), SMPN 8 Tangerang Selatan (400 m), SMAN 2 Tangerang Selatan (240 m), Sekolah Santa Laurensia (1,8 km), dan BINUS ASO School of Engineering $(1,3 \mathrm{~km})$. Sementara rumah sakit di sekitar Pasar 8, antara lain RS OMNI Alam Sutera $(800 \mathrm{~m})$, OMDC Alam Sutera $(1,5 \mathrm{~km})$, dan St. Carolus Hospital Serpong Summarecon $(4,7 \mathrm{~km})$.

Pasar 8 adalah satu dari sederet area komersial yang sukses dikembangkan PT Alam Sutera Realty Tbk. Tempat sejenis yang tidak kalah favorit di Alam Sutera adalah Flavor Bliss. Tempat yang dibangun sebagai pusat makanan dan hiburan keluarga bagi warga setempat ini dipenuhi oleh berbagai tenant makanan dari merek populer, seperti Starbucks Coffee, Sushi Tei, dan Bandar Djakarta. Flavor Bliss juga menempati area komersial yang sangat luas, yaitu dibangun di atas lahan seluas 7,7 hektar untuk memberi kepuasan jalan-jalan pengunjungnya.

Pasar 8 mudah diakses dari berbagai hunian di sekitarnya, seperti Alam Sutera - Sutera Buana, Alam Sutera Cluster Sutera Kirana, Alam Sutera Cluster Sutera Delima. Begitu pula dengan hunian yang ada di Jakarta, seperti di kawasan Ciledug dan sekitarnya, seperti Winong Asri, Griya Kencana 1, dan Bangun Reksa Indah 2. Ppasar 8 dan kondisi sekitar dapat dilihat pada Gambar 1 


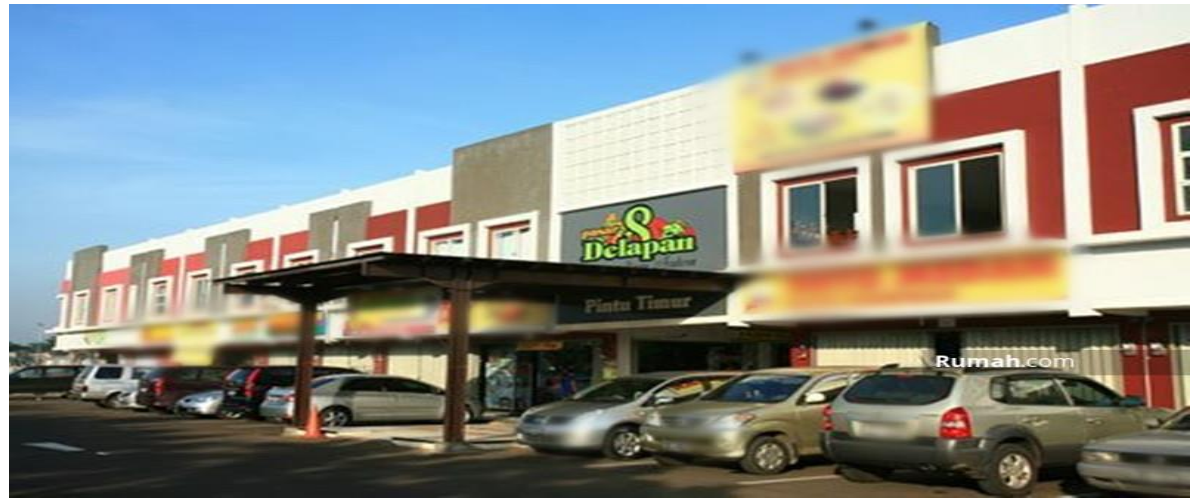

Gambar 1. Pasar 8

Pengemasan pasar tradisional menjadi pasar modern, seperti Pasar 8 tersebut, mampu menahan gempuran mal, supermarket, dan hypermarket. Dengan kondisi pasar modern seperti ini, setiap hari ratusan juta hingga miliaran rupiah uang beredar di sini.

Tempat belanja yang rapi dan mirip supermarket ini menemukan berbagai macam kebutuhan sehari-hari. Seperti sayur mayur, tahu, tempe, ikan, daging, ayam, dan masih banyak lagi. Tidak hanya itu saja, di pasar modern, ini juga berbelanja kebutuhan lainnya. Seperti pakaian, perlengkapan sekolah, sampai aneka boneka semuanya serba ada. Berbagai jenis yang diperdagangkan didalam pasar, sandang maupun pangan. Mulai dari kebutuhan pokok sehari-hari, beras sayur mayur, ikan, daging dagingan, bumbu bumbu sampai kepada kebutuhan sekunder lainnya seperti emas, pakaian, sepatu, perlengkapan rumah tangga dan lainnya.

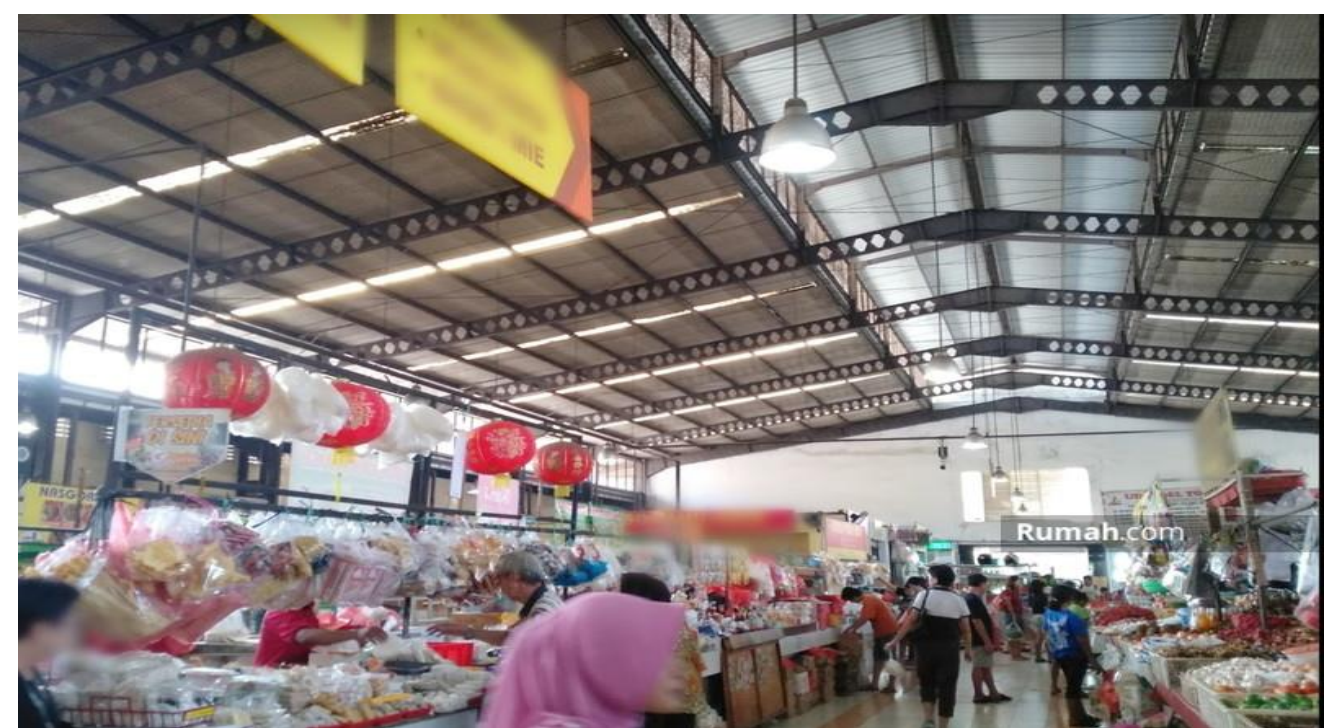

Gambar 2. Jenis Barang yang Diperdagangkan

\section{Profil Pedagang Ritel}

Kegiatan PKM dilakukan dengan mensosialisasikan customer relationship management (CRM), kepada pemilik toko ritel Wanty Collection. Pedagang ritel yang dipilih tergolong dalam usaha ritel produk pakaian. Toko ibu Wanty yang terdapat di pasar 8 dapat dilihat pada Gambar 3 . 


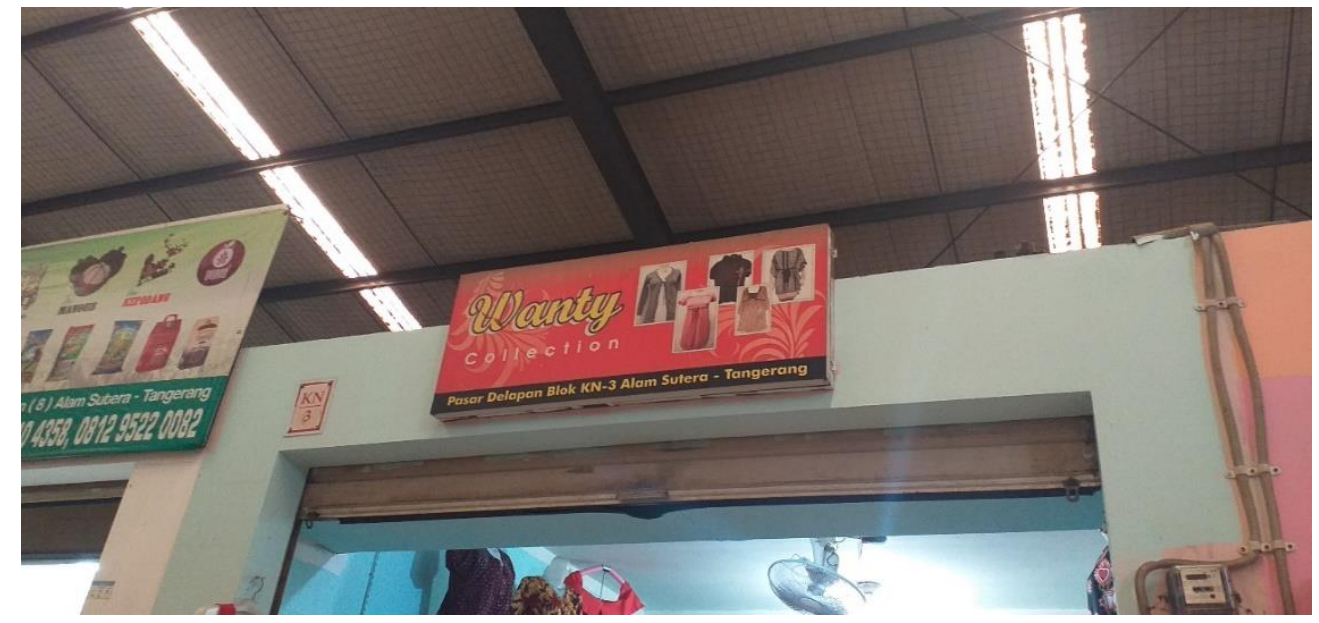

Gambar 3. Lokasi Toko Ritel Sari

Toko ritel tertelak di Blok KN-3 Alam sutera-Tangerang. Ibu Wanty adalah pemilik sekaligus pekerja ditoko, berdirinya toko baju ini sudah cukup lama sekitar 8 tahun. Ibu Wanty mendirikan usaha untuk turut membantu suami dalam memenuhi kebutuhan keluarga. Produk yang dijual bervariaai, namun rata rata pakaian wanita . Harga produk yang dijual juga bervariasi dari harga 60.000 ribu sampai 250 ribu. Dalam pengadaan produk dibeli dari pasar grosir Tanah Abang. Sistem penjualannya bisa grosir dan eceran, karena tidak semua pembeli bisa membeli dengan sistem grosiran dan sebaliknya. Dalam satu bulannya toko ini melakukan re-stock hingga 4 kali. Pelayanan dan kualitas barang sangat dipentingkan untuk memberikan kepuasan kepada konsumen atau pelanggan tetapnya. Namun kondisi saat ini ibu Wanty hanya hanya dapat melakukan re-stock 2 kali, bahkan kadang kadang hanya sekali. Barang dagangan yang dijual dapat dilihat pada Gambar 4.

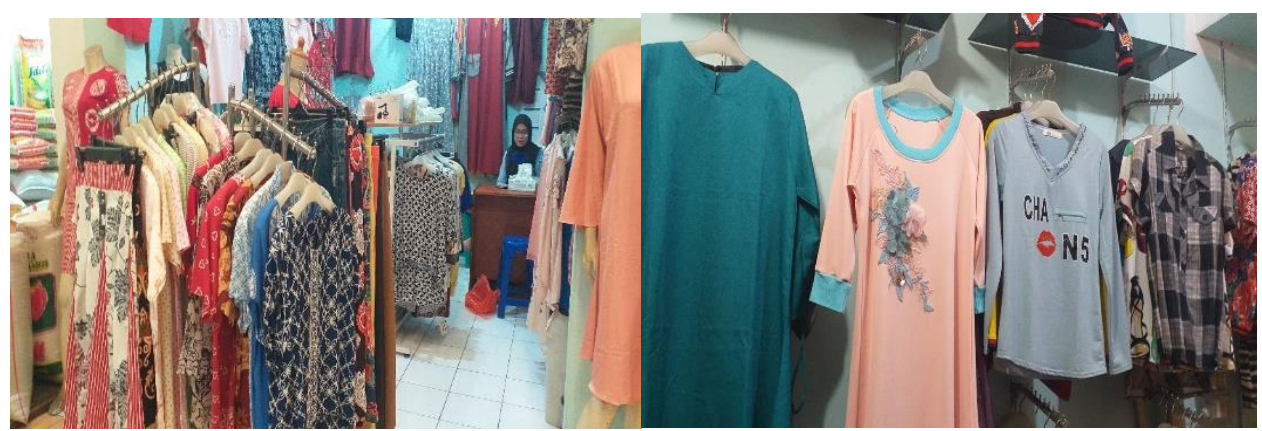

Gambar 4. Barang Dagangan yang Dijual

\section{Sosialisasi CRM}

Proses FDG dilakukan dengan pembuatan model panduan PPT CRM. Pemilik toko ritel harus memahami tentang CRM. Agar dapat mempertahankan dan meningkatkan hubungan yang langgeng dengan konsumen. Pemahaman tentang CRM tersebut bertujuan untuk lebih mengetahui bagaimana dan apa yang harus dilakukan dalam menjalin hubungan jangka Panjang dengan pelanggan . Spesifikasi materi pelatihan berupa pemahaman tentang pengertian CRM, proses CRM, customer database, Identifying Information, Pedoman FTC. Materi tersebut meliputi:

\section{Pengertian Customer Relationship Management/CRM}

adalah sebuah filosofi bisnis dan satuan strategis, program, dan sistem yang memfokuskan pengidentifikasian dan membangun hubungan dengan seorang pelanggan ritel yang berharga. 
CRM memudahkan para peritel untuk mengembangkan suatu dasar pelanggan yang setia dan meningkatkan share of wallet yaitu persentase dari pembelian pelanggan yang dibuat dari peritel.

\section{Proses CRM}

CRM adalah sebuah proses yang interaktif yang mengubah data pelanggan kedalam loyalitas pelanggan dan perilaku pembelian ulang melalui empat aktivitas: (1) mengumpulkan data pelanggan, (2) menganalisis data pelanggan dan mengidentifikasi pelanggan target, (3) mengembangkan CRM melalui program pembelanja yang seringkali, dan (4) mengimplementasikan program CRM. Proses tersebut dengan pengumpulan dan analisis terhadap data tentang seorang pelanggan peritel dan identifikasi terhadap pelanggan mereka yang terbaik. Analisis tersebut menterjemahkan data pelanggan kedalam informasi dan aktivitas yang menawarkan nilai kepada para pelanggan sasaran tersebut.

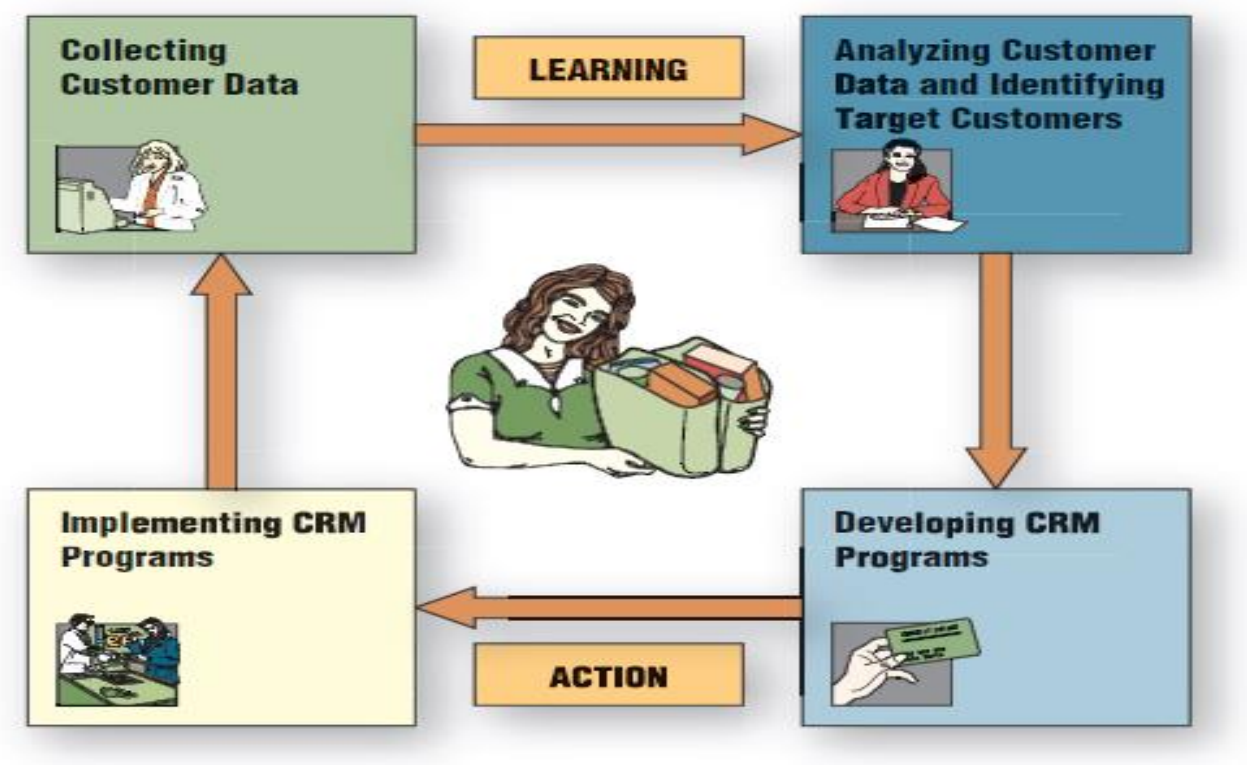

Gambar 5. Siklus Kegiatan CRM

Sumber: Levy (2012)

\section{Mengenalkan Customer Pyramid}

Pemilik toko perlu mehahami kedudukan dan posisi dari masing masing pelanggan, mengubah pelanggan dari yang belum setia menjadi pelanggan yang paling setia.

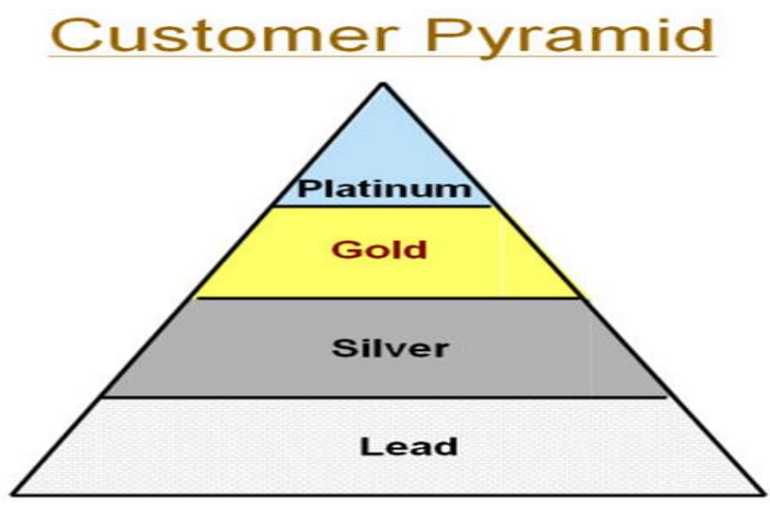

Gambar 6. Customer Pyramid

Sumber: Levy (2012) 


\section{Retensi pelanggan}

adalah pemeliharaan hubungan bisnis yang berkelanjutan dengan pelanggan dalam jangka panjang. Tingkatretensi pelanggan yang tinggi berbanding terbalik dengan pelanggan yang meninggalkan perusahaan

Customer Retention ada 2 :

1. Peronalization: batasan penting strategi CRM dikembangkan untuk segmen pasar, seperti segmen platinum di piramida pelanggan, adalah bahwa setiap segmen terdiri dari sejumlah besar pelanggan yang tidak identic

2. Community: pendekatan kedua untuk membangun retensi pelanggan dan loyalitas adalah untuk mengembangkan komunitas rasa di antara pelanggan

Proses sosialisasi tersebut dilakukan secara daring dengan menggunakan whatsapp seperti pada Gambar 7.

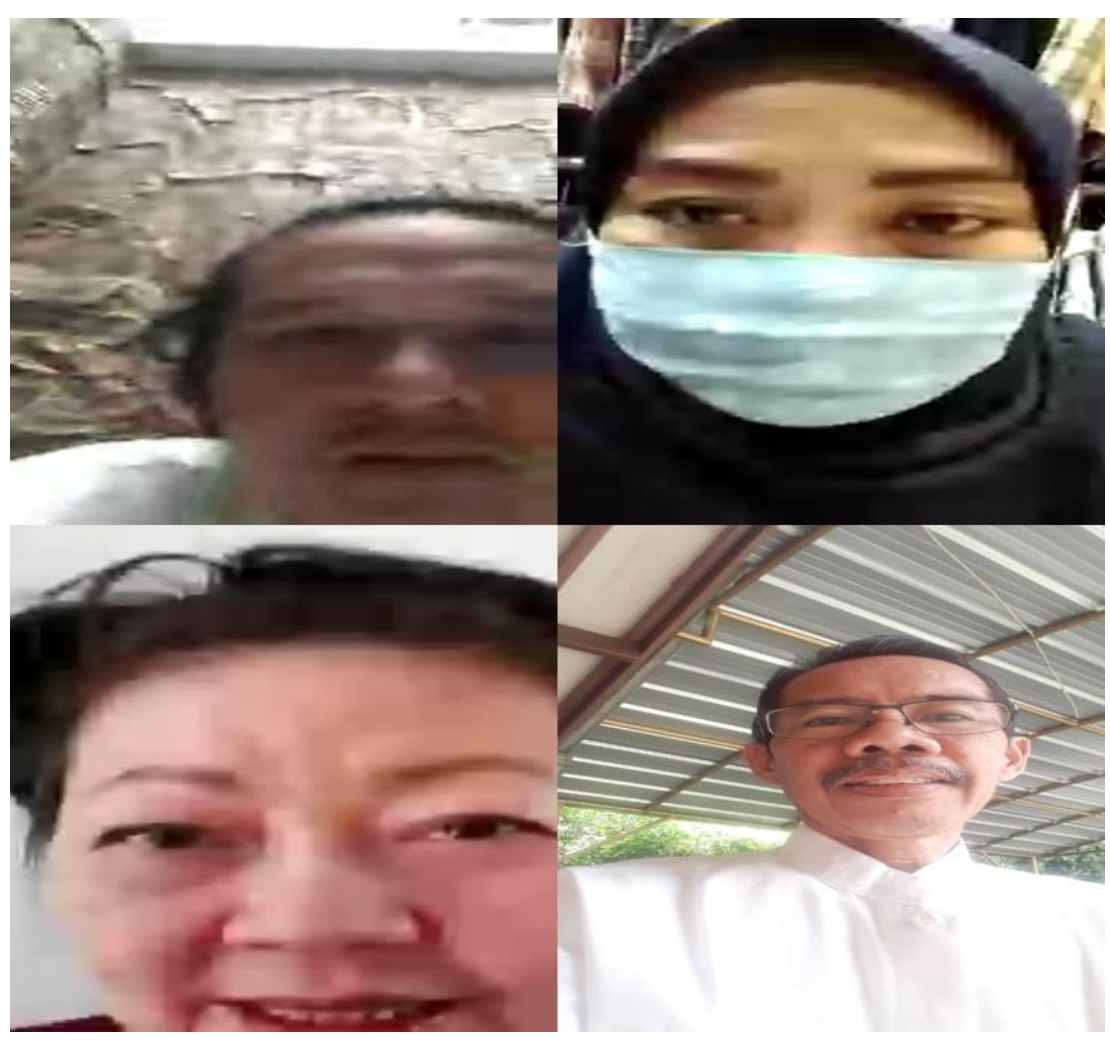

Gambar 7. Sosialisasi Secara Daring

\section{KESIMPULAN DAN SARAN}

\section{Kesimpulan}

Berdasarkan pelaksanaan kegiatan ini, diperoleh simpulan sementara sebagai berikut:

1. Panduan tentang CRM sudah tersusun dengan melakukan FGD, observasi dan wawancara secara daring dengan pihak terkait. Sosialisasi skala kecil sudah dilakukan pada mitra usaha ritel yang terdapat di pasar Delapan .

2. Pelatihan secara daring telah dilakukan dalam upaya meningkatkan pemahaman mitra tentang CRM, agar mitra dapat menjalankan bisnis secara berkelanjutan dan unggul dalam persaingan. 


\section{Saran}

Perbaikan secara berkelanjutan usaha ritel dapat dilakukan antara lain dapat dikembangkan dalam kajian selanjutnya.

1. Proses pembinaan kontinuitas usaha, melalui pemetaan terhadap permasalahan usaha ritel.

2. Melakukan kerja sama dengan mitra, untuk relokasi layout, display, pencahayaan yang sudah tidak layak lagi.

\section{Ucapan Terima Kasih (Acknowledgement)}

Pada kesempatan ini kami ingin mengucapkan terima kasih kepada semua pihak yang telah terlibat dalam kegiatan PKM ini, baik secara langsung maupun tidak langsung sehingga kegiatan ini telah dapat diselesaikan dengan baik dan lancar, terutama kepada Ketua LPPM Untar beserta stafnya yang telah mendanai kegiatan ini, dan pelaku bisnis ritel yang di wakili oleh Ibu Wanty sebagai mitra kerja dalam PKM ini, disamping pihak lainnya .

\section{REFERENSI}

Armstrong, Kotler (2015), “Marketing an Introducing Pretiece Hall twelfth edition”, England : Pearson Education, Inc

Berman, Barry and Joel R. Evans (2007), Retail Management: A Strategic Approach, 10th ed., Prentice Hall

Hasyim, Diana (2013). Kualitas Manajemen Keuangan Usaha Mikro Kecil Menengah (Umkm) (Studi Kasus Pada Distribution Store (Distro) Di Kota Medan), Jurnal Jupiis Vol 5 No 2

Hair, J. F., Anderson, R. E., Mehta, R., \& Babin, B. J. (2013). Sales Management : BuildingCustomer Relationships and Partnerships. Boston: Houghton Mifflin Co.

Levy, Michael and Barton A. Weitz (2012). Retailing Management. New York : McGraw-Hill Companies

Scarborough, Norman M, and Zimmerer, Thomas. W. (1996), Effective small bussines management. Fifth edition. Prentice hall, inc. New Jersey, USA

Thomas W Zimmerer, Norman M Scarborough (2008), Kewirausahaan dan Manajemen Usaha Kecil, Salemba empat, Jakarta 